\title{
EVALUASI KELAYAKAN HUTAN KOTA STUDI KASUS HUTAN KOTA SRENGSENG, JAKARTA BARAT
}

\author{
Randy Markho'), Suryono Herlambang ${ }^{2)}$, Parino Rahardjo ${ }^{3)}$, Suryadi Santoso ${ }^{4)}$ \\ 1)Program Studi S1 PWK, Fakultas Teknik, Universitas Tarumanagara, randymarkho@gmail.com \\ 2)Program Studi S1 PWK, Fakultas Teknik, Universitas Tarumanagara, s.herlambang@gmail.com \\ 3)Program Studi S1 PWK, Fakultas Teknik, Universitas Tarumanagara, parinor19@gmail.com \\ 4)Program Studi S1 PWK, Fakultas Teknik, Universitas Tarumanagara, josantosojkt@yahoo.com
}

Masuk: 12-08-2020, revisi: 28-09-2020, diterima untuk diterbitkan: 29-09-2020

\begin{abstract}
Abstrak
Hutan kota merupakan salah satu bagian terpenting di perkotaan. Dengan perkembangan fisik perkotaan yang terus terjadi membuat sulit dan mahal untuk menambah hutan kota. Padahal hutan kota mempunyai memberikan manfaat yang penting untuk masyarakat kota, seperti memberikan keseimbangan bagi ekosistem, sebagai areal resapan air, dan menjadi tempat daur karbondioksida menjadi oksigen. Salah satu hutan kota yang ada di Jakarta adalah Hutan Kota Srengseng. Pada penelitian kali ini ingin mengetahui apakah Hutan Kota Srengseng telah memenuhi kriteria sehingga layak disebut sebagai sebuah hutan kota. Metode yang digunakan pada penelitian ini adalah kualitatif, observasi lapangan dan studi literatur. Hasil penelitian ini akan mengetahui layanan ekosistem yang diberikan oleh Hutan Kota Srengseng dan potensi yang ada di Hutan Kota Srengseng sehingga dapat membuat rencana pengembangan dan pengelolaan Hutan Kota Srengseng yang optimal kedepannya.
\end{abstract}

Kata Kunci: Hutan Kota; Layanan Ekosistem; Perkotaan

\begin{abstract}
Urban forests are one of the most important parts in urban areas. With urban physical development that continues to occur makes it difficult and expensive to add urban forests. Whereas urban forests have important benefits for urban communities, such as providing a balance to ecosystems, as water catchment areas, and being a place of carbondioxide to oxygen cycles. One of the urban forests in Jakarta is Hutan Kota Srengseng. In this research, we want to find out whether Hutan Kota Srengseng meets the criteria so that it is worth mentioning as an urban forest. The method used in this research is qualitative, field observations and literature studies. The results of this study will find out the ecosystem services provided by the Hutan Kota Srengseng and the potential that exists in the Hutan Kota Srengseng so that they can make optimal plans for developing and managing Hutan Kota Srengseng in the future.
\end{abstract}

Keywords: Ecosystem Services; Urban; Urban Forest

\section{PENDAHULUAN}

\section{Latar Belakang}

Saat ini telah terjadi penurunan kualitas udara dan air yang tinggi khususnya di daerah perkotaan yang merupakan pusat peradaban kehidupan manusia sekarang. Pada awalnya, sebagian besar lahan perkotaan terdiri atas Ruang Terbuka Hijau (RTH), namun seiring meningkatnya kebutuhan manusia beserta ativitasnya maka terjadilah pengalihan penggunaan RTH secara besar-besaran. Di lain pihak, kemajuan alat dan pertambahan jalur transportasi dan sistem utilitas, sebagai bagian dari peningkatan kesejahteraan warga kota, juga telah menambah jumlah bahan pencemar dan telah menimbulkan berbagai ketidaknyamanan di lingkungan perkotaan.

Oleh karena itu, RTH sangat penting bagi kehidupan baik secara ekologis maupun sosial budaya. 
Salah satu RTH yaitu Hutan Kota, pentingnya hutan kota dapat berfungsi menyeimbangkan kondisi lingkungan diperkotaan. Hutan kota adalah suatu areal lahan perkotaan yang terdiri dari beberapa komponen fisik dengan vegetasi berupa pohon- pohon sebagai suatu kesatuan ekosistem yang berperan dan berfungsi untuk meningkatkan kualitas lingkungan hidup.

Salah satu hutan kota di Jakarta adalah Hutan Kota Srengseng. Hutan kota yang terletak di Jl. H. Kelik, RT.8/RW.6, Srengseng, Kec. Kembangan, Kota Jakarta Barat ini merupakan hutan kota milik Pemda Jakarta. Hutan Kota Srengseng disulap dari sebuah tempat pembuangan akhir sampah. Seiring dengan perkembangan waktu, tempat ini sudah tidak memungkinkan lagi menjalankan fungsinya. Oleh karena itu pemerintah DKI Jakarta mengubah fungsinya menjadi Ruang Terbuka Hijau (RTH). Tempat ini direhabilitasi dengan sistem gali uruk (sanitary landfill). Timbunan sampah yang terkumpul di urug dan ditutup dengan lapisan tanah.

Hutan Kota Srengseng ditetapkan sebagai hutan kota lewat Surat Keputusan Gubernur DKI Jakarta nomor 202 tahun 1995. Dalam surat keputusan tersebut kawasan Hutan Kota Srengseng difungsikan sebagai daerah resapan air, pengawetan plasma nuftah, tempat wisata dan aktifitas masyarakat. Pembangunan kawasan sudah dimulai sejak tahun 1993. Bahkan, persiapannya seperti pembebasan tanah sudah dimulai sejak tahun 1986. Hutan Kota Srengseng memiliki luas sebesar $15 \mathrm{Ha}$ dan terdapat danau buatan dengan luas 2 Ha. Tetapi karena adanya pembangunan Jl. Inkspeksi Kali Pesanggrahan Barat yang menggunakan lahan Hutan Kota Srengseng, maka luas total Hutan Kota Srengseng berkurang hingga menjadi -+13 Ha. Hutan Kota Srengseng memiliki setidaknya 5000 tumbuhan dan beberapa jenis hewan. Setidaknya terdapat 65 jenis pohon yang mendiami hutan seperti, Mahoni, Akasia, Ketapang, Bintaro, Lamboro, Flamboyan dan Jati.

\section{Rumusan Permasalahan}

Adapun rumusan permasalahan yang terdapat di Hutan Kota Srengseng terlihat dari kondisi lingkungan yang kurang dikelola dengan baik sehingga banyak fasilitas yang rusak hingga tidak dapat digunakan dan kebersihan yang kurang baik sehingga membuat pengunjung tidak ingin kembali mengunjungi Hutan Kota Srengseng. Hutan Kota Srengseng juga memiliki potensi yang kurang dimanfaatkan dengan baik, seperti danau dan pulaunya yang tidak dikembangkan sama sekali. Padahal dengan beragamnya flora dan fauna di Hutan Kota Srengseng dan juga keberadaan danau buatan dan pulau yang unik, dapat dijadikan sebagai tempat wisata rakyat dan sarana edukasi.

\section{Tujuan}

Tujuan dari penelitian ini adalah untuk mengetahui mengetahui apakah Hutan Kota Srengseng telah memenuhi kriteria sehingga layak disebut sebagai hutan kota dan mengetahui kekurangan dan kelebihan Hutan Kota Srengseng, sehingga dapat dikembangkan dan memaksimalkan kegunaan berdasarkan fungsinya.

\section{KAJIAN LITERATUR}

Hutan Kota didefinisikan sebagai kerapatan pohon, dan keanekaragaman pohon dengan luasan tertentu di perkotaan. Oleh Milller "didefinisikan, sebagai pendekatan untuk menyatukan kota yang luas dengan menggunakan tanaman, kepedulian, dan mengelola pohon di dalam kota terhadap keberadaan lingkungan yang majemuk dan keuntungan sosial untuk penduduk kota. (w.w.w.fao.org/docrep/005/t1680c/Ta 680Eo1)." Miller mendefinisikan "Hutan Kota adalah mengelola pohon agar dapat berkontribusi terhadap fisiologis, sosiologis, dan ekonomi kesejahteraan masyarakat kota", sedangkan Fukura berpendapat bahwa Hutan Kota merupakan ruang terbuka yang berada di perkotaan yang ditumbuhi dengan vegetasi berkayu yang 
memberi manfaat bagi lingkungan sebesar-besarnya, kepada penduduk kota dalam kegunaan proteksi, estetika, rekreasi khusus lainnya (Irwan, 1992).

Menurut Grey dan Deneke (1986), Hutan Kota merupakan pengelolaan pohon yang berkontribusi pada psikologis, sosiologis, dan kesejahteraan ekonomis masyarakat kota. Hutan Kota juga memberikan pengaruh kepada sumber alam yang lain. Pengaruh ini melalui tiga faktor lingkungan yang saling berhubungan, yaitu iklim, tanah, dan pengadaan air bagi berbagai wilayah.

Tabel 1. Manfaat Hutan Kota

\begin{aligned} & \hline \multicolumn{1}{c}{ Fungsi } \multicolumn{1}{c}{ Manfaat } \\ & \hline Ekologis - Menurunkan tingkat pencemaran udara \\ & - Meningkatkan kandungan air tanah, berakibat akan berkurangnya \\ & - penurunan muka tanah (land subsidence) \\ & - Perlindungan sumberdaya penyangga kehidupan (contoh air bersih) \\ & - Membangun jejaring habitat kehidupan liar (contoh untuk burung) \\ & \hline Psikologi Menurunkan tingkat stres masyarakat \\ & \hline Sosial Rekreasi \\ & \cline { 2 - 2 } Pendidikan lingkungan \\ & \hline\end{aligned}

Sumber: Grey dan Deneke, 1986

\section{Layanan Ekosistem}

Manusia memperoleh manfaat langsung dari berbagai barang ekosistem serta dari aktivitas dan produk organisme, baik dalam ekosistem liar maupun yang didominasi manusia (Daily et al. 1997; Levin dan Lubchenco 2008). Manfaat-manfaat dari alam ini telah tersedia sepanjang sebagian besar sejarah manusia. Sampai hari ini, masyarakat menerima begitu banyak jasa alam ini (Daily 1997, MEA 2005), bahkan ketika sistem pendukung yang menyediakannya mengalami degradasi parah (Vitousek et al. 1997; Levin dan Lubchenco 2008; Seppelt et al. 2011). Tantangan utama abad ini adalah untuk mengembangkan sistem ekonomi dan sosial dan sistem pendukung tata kelola dari skala lokal ke skala global yang akan mencapai tingkat populasi dan konsumsi manusia yang berkelanjutan sambil juga mempertahankan layanan pendukung kehidupan ekosistem yang menopang kesejahteraan manusia (Guerry et al. 2015).

Berbagai manfaat ekosistem bagi kehidupan manusia dikelompokkan dalam konsep "jasa ekosistem" (ES). Sejak konsep ini pertama kali diperkenalkan (Ehrlich dan Mooney 1983), ia telah berevolusi (Daily 1997; MEA 2005) menjadi fenomena global (mis., Kubiszewski et al. 2017). ES dapat secara singkat didefinisikan sebagai manfaat yang diperoleh manusia dari sistem ekologi (Levin dan Lubchenco 2008), yang terdiri dari aliran bahan, energi, dan informasi dari cadangan modal alam yang, bila dikombinasikan dengan layanan yang berasal dari modal manusia untuk menghasilkan kesejahteraan manusia (Costanza et al. 1997).

ES terdiri dari fungsi ekosistem, yang merujuk pada habitat, sifat biologis atau sistem atau proses ekosistem, dan juga barang ekosistem (seperti makanan) dan jasa (seperti asimilasi limbah) yang diperoleh populasi manusia, langsung atau tidak langsung, dari fungsi ekosistem (Costanza et al. 1997, 2014). Dimungkinkan untuk mengenali empat kategori ES (Gbr. 1): (i) layanan penyediaan atau penyediaan makanan atau habitat; (ii) layanan pengaturan, seperti regulasi erosi atau iklim; (iii) layanan pendukung, seperti produksi primer atau siklus nutrisi; dan (iv) layanan budaya, seperti kenikmatan estetika atau rekreasi (MEA 2005). Klasifikasi ini memunculkan pemahaman yang lebih luas tentang potensi penggunaan ES dan juga menyediakan kerangka kerja untuk menganalisis berbagai pengaruh, aktif dan pasif, dimana layanan ekosistem meningkatkan kesejahteraan manusia (Boyd dan Banzhaf 2007; Fisher et al. 2009). Namun demikian, sebagian 
besar fungsi dan layanan yang termasuk dalam salah satu dari empat kategori ES saling tergantung dan mendukung kesejahteraan manusia melalui kontribusi mereka terhadap produk bersama ekosistem (Costanza et al. 1997)

\section{METODE}

\section{Teknik Pengolahan Data}

Analisis Kebijakan

Menjadi dasar dalam melakukan sebuah pengelolaan Hutan Kota Srengseng sebagai objek wisata berbasis rekreasi dan edukasi agar sesuai dengan kebijakan yang telah ditentukan oleh pemerintah, sehingga dalam mengusulkan strategi pengelolaan tidak melanggar suatu apapun. Menggunakan metode desktiptif yang dilihat dari Peraturan Pemerintah Republik Indonesia dan undang-undang yang berlaku.

\section{Analisis Kondisi Fisik dan Eksisting Hutan Kota Srengseng}

Mengetahui kondisi eksisting dari Hutan Kota Srengseng sehingga dapat terlihat potensi dan permasalahan utama dari luar (eksternal) dan dari dalam (internal) kawasan. Selain itu, dilihat juga dari struktur organisasi beserta jobdesknya, dan juga pembiayaan berupa pendapatan dan pengeluaran di Hutan Kota Srengseng.

\section{Analisis Daya Dukung Kawasan}

Mengetahui daya tampung perhari yang idealnya mampu ditampung oleh Hutan Kota Srengseng berdasarkan luas areal kebutuhan per orang dan durasi kunjungan menggunakan metode kuantitatif yaitu rumus perhitungan areal hingga daya dukung fisik dan daya dukung ekologi

\section{Analisis Best Practice}

Melihat kunci keberhasilan strategi pengelolaan dengan konsep yang sama dan ditinjau berdasarkan faktor eksternal dan internal kawasan. Dengan cara mencari, menelah serta menganalisis objek studi lain yang memiliki karakteristik dan pengelolaan dari objek studi yang diteliti dengan konsep yang sama yaitu Hutan Kota Srengseng.

\section{Analisis Perbandingan Taman Kota dan Hutan Kota}

Memperoleh karakteristik Hutan Kota Srengseng yang sebenarnya untuk dapat menjadi dasar evaluasi.

\section{Analisis Pengelolaan}

Memperoleh usulan yang dapat digunakan untuk strategi pengelolaan Hutan Kota Srengseng guna meningkatkan kepuasan pengunjung dan tetap mempertahankan keberadaannya sebagai taman wisata alam yang berkonsep ecotourism dengan menggunakan metode deskriptif..

\section{Alat Analisis}

Metode Deskriptif

Metode ini merupakan secara kualitatif dilakukan untuk mendeskripsikan kondisi Hutan Kota Srengseng sehingga dapat menjelaskan karakteristik Hutan Kota Srengseng.

\section{Benchmark}

Metode ini digunakan untuk melakukan perbandingan objek studi yaitu Hutan Kota Srengseng dengan objek studi lain yang memiliki kondisi dan konsep yang sama dengan objek studi peneliti kemudian untuk dilihat kunci keberhasilannya berdasarkan pengelolaan terkait permasalahan yang ada dan cara penyelesaiannya. 


\section{DISKUSI DAN HASIL}

\section{Analisis Kebijakan Hutan Kota di Jakarta}

\section{Pergub No 17 tahun 2017 DKI Jakarta}

Pergub no 17 tahun 2017 DKI Jakarta sendiri disahkan oleh Plt. Gubernur saat itu yaitu Sumarsono dalam rangka menjamin kepastian hukum terselenggaranya penunjukan, pembangunan, penetapan dan pengelolaan Hutan Kota pada kawasan tertentu guna mewujudkan kelestarian dan keseimbangan ekosistem perkotaan khususnya di DKI Jakarta. Pergub tersebut menjamin seluruh kegiatan yang berhubungan dengan hutan kota yang terletak di Jakarta. Isi Pergub no 17 tahun 2017 sendiri kurang lebih sama dengan PP 63 dan Permenhut $P, 71$. Karena hierarki peraturan dan perundang-undangan di Indonesia mengatakan setiap pemerintah daerah perlu untuk memiliki peraturan sendiri agar dapat dijadikan landasan hukum tetapi tetap harus berintegrasi dengan peraturan pemerintah pusat.

\section{RPJMD DKI Jakarta Tahun 2017-2022}

RTH masuk dalam rencana pembangunan kota lestari DKI Jakarta pada RPJMD DKI Jakarta tahun 2017-2022. Hukum Indonesia sendiri mengatakan hutan kota termasuk dalam RTH. Adapun rencana penyediaan dan pengelolaan RTH tahun 2017-2022 adalah sebagai berikut:

a. Peningkatan Kuantitas Ruang Terbuka Hijau.

b. Optimalisasi Fungsi Ruang Terbuka Hijau.

c. Revitalisasi Ruang Terbuka Hijau.

d. Peningkatan kesadaran masyarakat untuk menjaga RTH.

Hutan Kota Srengseng termasuk didalam 3 pilot project Dinas Kehutanan Jakarta tahun 2019 dengan total nilai anggaran sebesar Rp16.000.000.000, dimana pekerjaan revitalisasi hutan telah dimulai pada awal tahun 2020. Revitalisasi sendiri dilakukan dengan memperbaiki fasilitas yang sudah ada, tanpa adanya rencana pengembangan baru.

\section{Analisis Kondisi Eksisting Hutan Kota Srengseng}

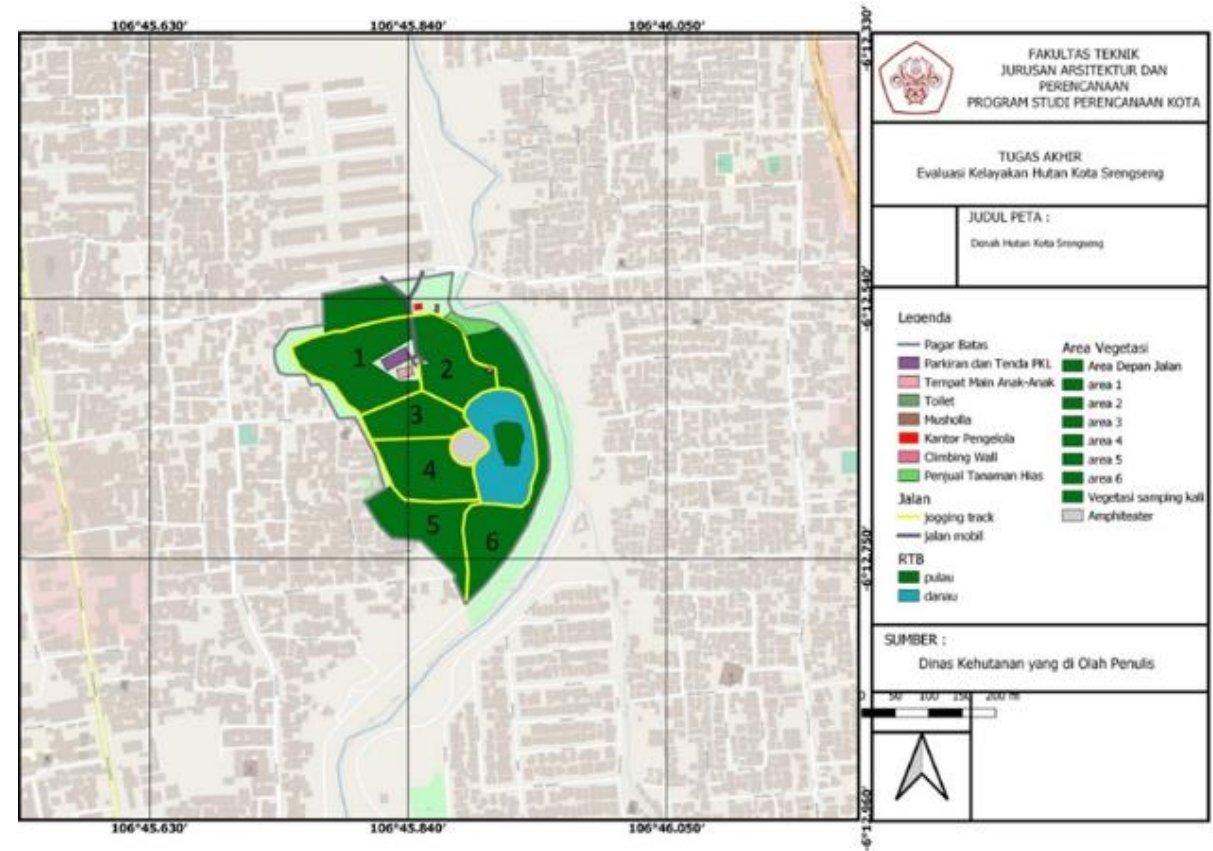

Gambar 1. Denah Hutan Kota Srengseng

Sumber: hasil olahan penulis, 2020 
Tabel 1. Luas Area Vegetasi Hutan Kota Srengseng

\begin{tabular}{cc}
\hline Area & Luas (m2) \\
\hline Depan Jalan & 6685 \\
\hline 1 & 15112 \\
\hline 2 & 10568 \\
\hline 3 & 8049 \\
\hline 4 & 11144 \\
\hline 5 & 11046 \\
\hline 6 & 8746 \\
\hline Samping Kali & 8811 \\
\hline Pulau & 2178 \\
\hline Danau & 16000 \\
\hline
\end{tabular}

Sumber: survey lapangan, 2020

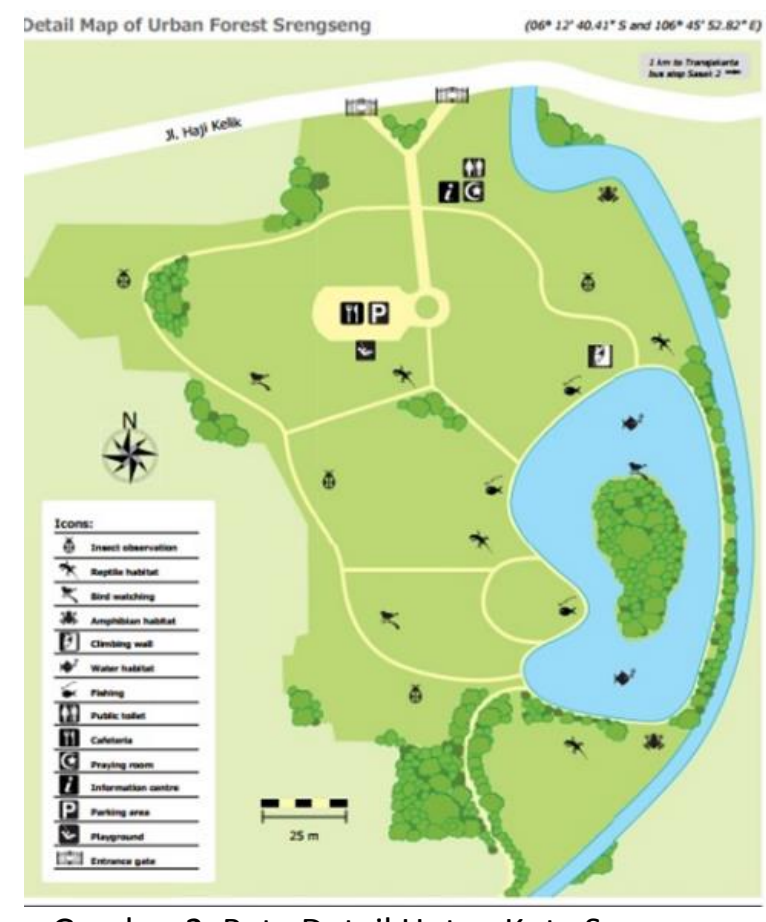

Gambar 2. Peta Detail Hutan Kota Srengseng Sumber: forclime

Tabel 2. Hard Material di Hutan Kota Srengseng

\begin{tabular}{ccc}
\hline No & Elemen & Ukuran \\
\hline 1 & Parkiran & $1.000 \mathrm{~m} 2$ \\
\hline 2 & Tenda Penjual Makanan & $80 \mathrm{~m} 2$ \\
\hline 3 & Kantor Pengelola & $152 \mathrm{~m} 2$ \\
\hline 4 & Tempat bermain anak & $310 \mathrm{~m} 2$ \\
\hline 5 & Musholla & $50 \mathrm{~m} 2$ \\
\hline 6 & Toilet & $18 \mathrm{~m} 2$ \\
\hline 7 & Climbing wall & $50 \mathrm{~m} 2$ \\
\hline 8 & Amphiteater & $2.203 \mathrm{~m} 2$ \\
\hline 9 & Pendopo & $25 \mathrm{~m} 2$ \\
\hline 10 & Lampu Taman & \\
\hline 11 & Papan Informasi & \\
\hline 12 & Tempat Sampah & $1.891 \mathrm{~m}$ \\
\hline 13 & Jogging Track & $1.500 \mathrm{~m}$ \\
\hline 14 & Pagar Pembatas &
\end{tabular}

Sumber: hasil survey lapangan, 2019 
Fasilitas yang ada di Hutan Kota Srengseng sendiri pada umumnya cukup terawat dengan baik, hanya beberapa fasilitas yang tidak pernah digunakan yang tidak terurus seperti lampu taman. Lampu taman sendiri tidak digunakan karena Hutan Kota Srengseng hanya terbuka untuk umum dari pukul 06.00-18.00 WIB. Luas area vegetasi di Hutan Kota Srengseng sendiri sekitar 9 ha, atau $70 \%$ dari luas lahan total.

\section{Analisis Daya Dukung Kawasan Ecosystem Services}

\section{Provisioning Services}

Layanan provisioning adalah suatu produk yang dihasilkan suatu ekosistem. Karena Hutan Kota Srengseng tidak seperti hutan pada umumnya, maka layanan provisioning yang diberikan tidak sebanyak seperti hutan-hutan yang lain. Hutan Kota Srengseng sendiri memiliki pohon besar sebanyak kurang lebih 5000 dengan ukuran dan umur yang berbeda-beda. Pada saat pohonpohon tersebut melakukan proses fotosintesis, pohon-pohon tersebut akan menyerap karbondioksida dan melepaskan oksigen sehingga memberikan kenyamanan dan ketentraman kepada setiap orang yang berada di Kawasan Hutan Kota Srengseng. Baik yang sedang melakukan aktifitas seperti sedang berolah raga, maupun kepada warga yang hanya ingin bersantai.

\section{Regulation Services}

Layanan regulasi sendiri merupakan salah satu layanan yang diberikan oleh yang berasal dari proses regulasi yang terjadi di Hutan Kota Srengseng kepada warga, khususnya yang tinggal di sekitar Hutan Kota Srengseng.

\section{a. Resapan Air}

Luas daerah soft material di Hutan Kota Srengseng sebesar 86.839 m2, luas danau 16.000 $\mathrm{m} 2$. Berdasarkan fungsinya, sebuah ruang terbuka hijau dapat menyerap air sebanyak 900 $\mathrm{m} 3 / \mathrm{ha}$. Dengan luas area vegetasi sebesar 9 ha, dan luas waduk sebesar 1,6 ha dengan tinggi danau $3 \mathrm{~m}$ Hutan Kota Srengseng dapat menampung air hingga $10000 \mathrm{~m} 3$. Sehingga dapat mengurangi banjir di kawasan Srengseng, dan dapat menampung sebagian luapan air dari sungai Pesanggarahan.

b. Kebisingan

Hutan Kota Srengseng juga memiliki 65 jenis pohon dengan jumlah kurang lebih sekitar 5000. Kebisingan merupakan bentuk suara yang tidak diinginkan atau bentuk suara yang tidak sesuai dengan tempat dan waktunya (Warningsih 2006). Suratmo 9 (1995) menyebutkan bahwa kebisingan merupakan bentuk suara yang tidak diinginkan karena menimbulkan kerugian terhadap manusia dan lingkungan. Haverbeke (1974) menyebutkan bahwa kerapatan, tinggi, panjang dan lebar (ketebalan) jalur/sabuk hijau merupakan faktor paling efektif dalam mereduksi kebisingan dibandingkan dengan ukuran daun dan karakteristik percabangan. Hutan dapat menyerap sekitar 6-8 desibel per 30 meter. Kerapatan tanaman lebih penting daripada spesies tanaman untuk mengurangi kadar kebisingan (Irwan 1994). Hasil penelitian Irwan (1994) menunjukkan bahwa hutan kota dapat menurunkan kebisingan sebesar $18,94 \%$ di siang hari pada awal musim hujan. Hutan kota berstrata banyak lebih efektif menurunkan kebisingan sebesar $25,34 \%$ dibandingkan dengan hutan kota berstrata dua yang dapat menurunkan kebisingan sebesar $14,58 \%$. Keefektifan penangkal kebisingan semakin meningkat dengan meningkatnya ketebalan, tinggi dan kerapatan tanaman (Grey \& Deneke 1986) Dengan kerapatan tumbuhan di Hutan Kota Srengseng sebanyak 2.570 spesies/ha dapat disimpulkan Hutan Kota Srengseng dapat menurunkan kebisingan sebesar lebih dari $25,34 \%$.

\section{Cultural Services}


Layanan budaya adalah keuntungan non material yang didapat dari ekosistem. Layanan budaya sendiri merupakan layanan yang paling banyak diberikan oleh Hutan Kota Srengseng dibanding layanan lain.

a. Rekreasi dan Wisata

Hutan Kota Srengseng menjadi salah satu tempat rekreasi dan olah raga untuk warga Jakarta. Banyak warga yang datang untuk berolah raga, seperti jogging, bersepeda, memancing, atau pun hanya untuk sekedar bersantai. Pada saat weekend, terlihat warga datang ke lokasi Hutan Kota Srengseng beserta keluarga untuk melakukan piknik. Tarif untuk masuk ke Hutan Kota Srengseng pun sangat terjangkau, dimana kendaraan roda 4 dikenakan tarif Rp 4.000, kendaraan roda 2 Rp 2.000, dan tarif Rp 2.000 untuk tiap orang.

b. Hubungan Sosial

Hubungan sosial pada Hutan Kota Srengseng terjadi pada saat warga yang datang melakukan aktivitas bersama. Pada saat melakukan aktivitas di Hutan Kota Srengseng, dapat bertemu dengan warga yang juga sedang melakukan aktivitas di tempat yang sama sehingga dapat berbincang antara satu dengan yang lain. Tentu hal ini memberikan bukti Hutan Kota Srengseng dapat menjadi wadah untuk hubungan sosial.

c. Estetika

Hutan kota sendiri menjadi suatu hal yang langka ditemukan di kota-kota metropolitan. Karena itu Hutan Kota Srengseng memiliki estetika sendiri sebagai salah satu hutan yang berukuran cukup besar dibanding hutan lainnya yang terletak di tengah-tengah kota. Oleh karena itu, Hutan Kota Srengseng biasa digunakan sebagai tempat untuk melaksanakan acara, seperti ulang tahun, pernikahan, foto pre-wedding, acara suatu ormas, dan sebagai tempat pengambilan gambar untuk pembuatan film.

d. Edukasi

Edukasi sendiri memiliki potensi yang sangat besar yang kurang dimanfaatkan pada Hutan Kota Srengseng. Pengelola Hutan Kota Srengseng hanya menjaga kondisi fisik hutan kota, tanpa memberikan edukasi optimal pada pengunjung. Padahal Hutan Kota Srengseng sering menjadi tujuan sekolah-sekolah atau universitas sebagai dalam melaksanakan study tour. Biasanya anak-anak sekolah tersebut diberikan informasi oleh guru mereka. Dan pada setiap akhir study tour, biasanya dilakukan penanaman pohon oleh anak-anak tersebut. Hal tersebut merupakan suatu yang sangat baik, hanya saja terkesan kurang maksimal karena penanaman pohon dilakukan secara asal (pemilihan bibit). Padahal jika dipersiapkan dengan baik, pohon-pohon yang ditanam tersebut dapat bertahan dan tumbuh berkembang dalam waktu yang panjang.

\section{Supporting Services}

Layanan yang diperlukan untuk produksi semua layanan ekosistem lainnya. Biasanya tumpeng tindih dengan layanan ekosistem lainnya (seperti erosi yang tumpang tindih antara regulation dengan supporting services). Penyediaan habitat sendiri merupakan salah satu layanan terpenting dari Hutan Kota Srengseng. Karena kota yang terus berkembang, jumlah manusia terus bertambah sehingga makhluk hidup lainnyta semakin sulit untuk mencari tempat tinggal. Karena itu, lahan Hutan Kota Srengseng sendiri sangat penting sebagai habitat makhluk hidup lainnya terutama hewan. Hutan Kota Srengseng sendiri menjadi rumah dari beberapa hewan, seperti burung air raja udang (Halyon chloris) burung emprit (Longchura sp) dan beberapa jenis kadal (Mabuai sp), biawak (Varanus salvator), ular tanah, ular air, tikus dan katak. Sedangkan beberapa jenis serangga yang ditemukan meliputi kupu-kupu kuning, belalang, gangsir dan orong-orong. Hutan Kota Srengseng sendiri menjadi salah satu habitat yang baik karena memiliki sumber daya yang dapat mendukung suatu ekosistem, dimana mempunyai sumber air pada Sungai Pesanggrahan dan Danau Srengseng. Dan juga terdapat tumbuhan-tumbuhan yang dapat menjadi makanan burung-burung tersebut, dan beberapa satwa kecil seperti katak dan tikus 
yang dapat menjadi makanan ular. Sehingga dapat disimpulkan Hutan Kota Srengseng memenuhi unsur sebagai menjadi sebuah ekosistem yang baik.

\section{Analisis Best Practice}

Analisis best practice digunakan digunakan untuk mendapatkan contoh konsep pengelolaan dari objek yang mempunyai fungsi yang sama kemudian dibandingkan dengan Hutan Kota Srengseng sehingga dapat dijadikan acuan untuk meningkatkan pengelolaannya. Benchmark yang di jadikan acuan di penelitian ini adalah Hutan Kota Arboretum Ir. Lukito Daryadi, M.Sc. Arboretum atau yang dulu bernama Taman Hutan Persahabatan dibangun pada tahun 1978. Arboretum sendiri memiliki 52 jenis pohon. Setiap pohon dilengkapi dengan barcode sehingga sangat mudah untuk mencari informasi tentang pohon-pohon tersebut, hanya dengan menscan barcodenya. Salah satu kebijakan yang sangat baik yang diterapkan di Arboretum adalah zero plastic policy, dimana pengunjung dihimbau untuk tidak membawa makanan atau minuman berbungkus plastik di areal Arboretum. Arboretum juga memiliki beberapa satwa yang hidup dikawasannya, seperti burung, kadal, dan katak. Dan yang menjadi daya tarik utama di Arboretum adalah Arborea Café. Arborea Café adalah sebuah café 2 lantai yang terletak di tengah Arboretum. Arborea Café sendiri memiliki waktu operasional dari 08.00-21.00 pada weekday, dan 11.00-21.00 pada weekend. Arborea Café menawarkan berbagai jenis makanan dan minuman dengan kisaran harga Rp30.000-Rp50.000. Arborea Café juga menyiapkan stop kontak dan free wifi, sehingga dapat dijadikan tempat bekerja atau mengerjakan tugas. Setiap dua minggu sekali di Jumat sore, Arboretum mengadakan konser live music yang dapat dinikmati pengunjung secara gratis. Arboretum sendiri tidak memungut biaya untuk masuk ke kawasannya.

\section{Analisis Pengelolaan Hutan Kota}

Pengelolaan hutan kota yang ada di Jakarta, terutama yang dikelola oleh pemda sendiri terkesan kurang jelas karena tidak adanya perencanaan dan prosedur dalam pengelolaan tersebut. Pengelola Hutan Kota Srengseng sendiri tidak memiliki SOP dalam mengelola hutan. Pamdal Hutan Kota Srengseng yang berjumlah 6 orang hanya bertugas menjaga keamanan dan menjaga fasilitas di kawasan hutan, menjual tiket masuk kawasan hutan, dan menjaga ketertiban di dalam kawasan hutan. Untuk kebersihan hutan sendiri, para petugas pamdal dibantu oleh PPSU Kelurahan Srengseng. Karena itu perlu dibuat suatu rencana kerja yang baik agar dapat menjaga keberlangsungan Hutan Kota Srengseng, seperti:

a. Membuat SOP perawatan fasilitas yang ada di Hutan Kota Srengseng, terutama investaris pohon. Pendokumentasian yang akurat dan lengkap akan membantu untuk membuat perencanaan yang baik kedepannya.

b. Perlu adanya jadwal rutin pemeliharaan fasilitas.

c. Perlu memberikan pelatihan kepada petugas bekerja oleh ahli di bidangnya agar petugas dapat bekerja secara efektif dalam merawat hutan kota.

d. Perlu memberikan sosialisasi dan edukasi secara rutin untuk masyarakat.

e. Perlu tindakan tegas kepada para pengunjung yang melanggar aturan di dalam kawasan Hutan Kota Srengseng.

Berdasarkan Pergub DKI Jakarta No 17 Tahun 2017 pasal 12, 13 dan 15, saat ini Hutan Kota Srengseng termasuk sebagai hutan tipe kawasan permukiman dan hutan tipe rekreasi yang artinya: 1) Dibangun di areal permukiman, yang berfungsi sebagai penghasil oksigen, penyerap karbondioksida, peresap air, penahan angin, peredam kebisingan, berupa jenis komposisi tanaman pepohonan tinggi dikombinasikan dengan tanaman perdu dan rerumputan; 2) Berfungsi sebagai pemenuhan kebutuhan rekreasi dan keindahan, dengan jenis pepohonan dan indah dan unik. 
Berdasarkan kondisi Hutan Kota Srengseng, dapat disimpulkan Hutan Kota Srengseng lebih tepat untuk dikembangkan sebagai sebuah taman kota. Mengapa taman kota? Menurut (Grey, 1996:10-20) taman kota adalah ruang di dalam kota yang strukturnya bersifat alami dengan sedikit bagian yang terbangun. Taman ini berisi beraneka pepohonan dan sering juga terdapat lahan terbuka yang luas sebagai tempat aktivitas olah raga dan aktifitas lainnya. Taman ini berfungsi sebagai tempat berteduh, perlindungan terhadap angin, penyerapan cahaya matahari dan sebagai penunjang kepuasan dan kesenangan melalui fasilitas yang ada didalamnya. Pengembangan dengan konsep taman kota dapat dilakukan dengan pembangunan fasilitas dengan seminimal mungkin sehingga tidak mengganggu ekosistem yang ada didalamnya.

\section{KESIMPULAN DAN SARAN}

\section{Kesimpulan}

Hutan Kota Srengseng belum memenuhi kriteria sebagai hutan kota yang optimal karena untuk menjadi sebuah hutan kota yang optimal perlu memiliki provisioning services yang tangible, seperti air bersih, makanan, atau tumbuhan obat-obatan. Provisioning services yang disediakan Hutan Kota Srengseng saat ini berupa udara bersih dan memberikan rasa kenyamanan dan ketentraman kepada pengunjung hutan kota dan kepada warga yang tinggal disekitar kawasan. Tapi untuk ecosystem services lainnya, regulation, cultural dan supporting sudah cukup baik disediakan oleh Hutan Kota Srengseng.

Pengelolaan Hutan Kota Srengseng kurang optimal karena tidak adanya rencana pengelolaan atau sop tertentu yang diterapkan dalam pengelolaan. Petugas hanya menjaga fasilitas yang ada dan melakukan pergantian tanaman jika melihat ada pohon yang rusak dan kebersihan kawasan hutan dibantu oleh PPSU Kelurahan Srengseng.

Hutan Kota Srengseng sendiri memiliki beberapa fasilitas yang dapat mendukung aktifitas di dalam kawasan hutan, seperti jogging track, tempat bermain anak-anak, dan amphiteater. Tentu jumlah fasilitas yang ada terbilang minim untuk suatu hutan kota yang dideskripsikan sebagai hutan rekreasi

\section{Saran}

Dari penelitian yang telah dilakukan diatas adapun rekomendasi yang dapat dilakukan untuk memaksimalkan potensi yang ada di Hutan Kota Srengseng, yaitu:

a. Membuat suatu SOP pengelolaan hutan kota yang dibantu oleh ahli yang sesuai dengan bidangnya.

b. Menambah beberapa fasilitas seperti jembatan, pujasera dan alat gym portable. Fasilitasfasilitas tersebut dapat menjadi salah satu daya tarik baru untuk mengunjungi Hutan Kota Srengseng, menambah pilihan aktifitas yang dapat dilakukan dan fasilitas-fasilitas tersebut dapat dibangun tanpa mengurangi fungsi ekologis dari Hutan Kota Srengseng.

c. Memberikan pelatihan kepada SDM yang akan bekerja untuk mengelola hutan.

d. Melaksanakan sosialisasi rutin kepada pengunjung maupun warga sekitar tentang pentingnya sebuah hutan kota, serta memberi edukasi tentang tumbuhan dan hewan yang hidup dalam kawasan Hutan Kota Srengseng.

\section{REFERENSI}

Asimgil, B. (2012). Sustainable Planning of Urban Parks - The Case of Balıkesir, Turkey

Chiesura, A. (2003). The role of urban parks for the sustainable city.

Carter, E. J. (1993). The Potential of Urban Forestry in Developing Countries

FORCLIME. Urban Forest Open Green Space and Biodiversity in Jakarta- A Guide to Jakarta

Remaining Wildlife Habitat. 
Konijnendijk, C. C., Annerstedt, M., \& Maruthaveeran, S. (2013). Benefits of Urban Parks, A systematic review, A Report for IFPRA. Copenhagen \& Alnarp

Lee, Y.-C., Kim, K.-Ho. (2015). Attitudes of Citizens towards Urban Parks and Green Spaces for Urban Sustainability: The Case of Gyeongsan City, Republic of Korea

Loures, L., Santos, R., \& Panagopoulos, T. (20017). Urban Parks and Sustainable City Planning The Case of Portimão, Portugal.

Ordóñez, C., \& Duinker, P. (2010). Interpreting Sustainability for Urban Forests

Steenberg, J., Robinson, P. J., \& Nowak, D. J. (2016). A Conceptual Framework of Urban Forest Ecosystem Vulnerability.

Subarudi, e. a. (2014). Subarudi, et al. 2014, "Sintesis Penelitian Integratif Pengembangan Hutan Kota pada Lanskap Perkotaan. Bogor: Pusat Penelitian dan Pengembangan Perubahan Iklim dan Kebijakan, Badan Penelitian dan Pengembangan Kehutanan.

Rahardjo, P. (2011). Hutan Kota Sebagai Upaya Memperbaiki Ekosistem Kota (Kasus Kota Jakarta). Seminar Nasional Temu Dosen Fakultas Teknik. Jakarta: Fakultas Teknik Universitas Tarumanagara. 
